\title{
Relationship Between Bud Cold Hardiness and Budbreak in Two Vitis vinifera L Cultivars, Chardonnay and Thompson Seedless
}

\author{
Francisco J. Pérez ${ }^{1}$ (D) Sebastián Rubio ${ }^{1}$
}

Received: 27 November 2020 / Accepted: 10 February 2021 / Published online: 6 March 2021

(c) The Author(s) 2021

\begin{abstract}
The lack of winter cold is a severe limitation for the cultivation of grapevines (Vitis vinifera $\mathrm{L}$ ) in areas with warm winter climates. This phenomenon is currently becoming quite important due to global warming, which will increase winter temperatures in many temperate regions of the planet where grapevines are cultivated. Although various physical and chemical stimuli have been used to address the lack of winter cold in grapevine cultivation, quantitative studies on its effects on different cultivars are limited. Here, the effects of (a) low temperatures during endodormancy (ED), (b) temperature increases during eco-dormancy (ECD) and (c) the effects of dormancy-breaking compounds such as hydrogen cyanamide (HC) and sodium azide (AZ) on the budburst of an early budbreak cultivar, Chardonnay, and an late budbreak cultivar, Thompson seedless, were assessed. The results were analysed by the Kaplan-Meier method, and the log-rank test was used to establish statistical significance between the control and treatments. In general, Chardonnay grapevines were more sensitive than Thompson seedless grapevines to all budbreak stimuli, and a temperature increase during ECD was the stimulus that had the greatest effect on the budbreak in both cultivars. Exposure to cold temperatures during ED increased the cold hardiness and improved the budbreak in both cultivars. Based on the results, a relationship between the degree of bud cold hardiness and budbreak potential is suggested, and it is proposed that the greater the cold hardiness achieved by the buds, the better their subsequent budbreak will be.
\end{abstract}

Keywords Endodormancy $\cdot$ Bud cold hardiness $\cdot$ Grapevines

\section{Introduction}

Most deciduous fruit trees grown under temperate climatic conditions experience a period of growth recess or endodormancy (ED) during the autumn-winter season. For grapevines, ED is triggered by the short-day (SD) photoperiod (Kühn et al. 2009; Grant et al. 2013; Cragin et al. 2017) and is preceded by growth arrest. At the physiological and metabolic level, the ED in the grapevine buds is characterized by a decrease in respiration and metabolism (Parada et al. 2017), the arrest of cell division (Vergara et al. 2017), the accumulation of starch (Rubio et al. 2019), and the thickening of the cell wall of the bud meristematic cells (Dantas et al. 2020). ED in grapevines

Handling Editor: Rhonda Peavy.

Francisco J. Pérez

frperez@uchile.cl

1 Facultad de Ciencias, Laboratorio Bioquímica Vegetal, Universidad de Chile, Casilla 653, Santiago, Chile is important since it allows the survival of the bud throughout the winter, prevents its sprouting in response to transient warm spells during the winter (Jian et al. 1997) and is essential for the development of cold hardiness (Rubio et al. 2016; Cragin et al. 2017). It is generally believed that low winter temperatures in deciduous fruit trees promote the release of buds from ED (Faust et al. 1997; Campoy et al. 2011) and that the accumulation of a certain amount of cold during the autumn-winter season is required for bud dormancy release (Arora et al. 2003; Rinne et al. 2011). However, the low temperatures also induce bud cold hardiness, which could also be related to their budding (Rubio et al. 2019). However, regardless of the role of low winter temperatures, these are required to produce a high and homogeneous budbreak in the spring, and when they are lacking, the commercial production of most deciduous fruit trees, including grapevines, is limited (Lavee and May 1997; Dokoozlian 1999). In the context of climate change, the ED and cold hardiness of deciduous fruit trees is increasingly attracting the attention of researchers and growers. Warmer winters can cause striking and unpredictable effects on deciduous fruit 
trees by advancing or delaying phenological stages such as flowering, fruit ripening or leaf senescence (Luedeling et al. 2009; Luedeling 2012). To overcome this problem, various chemical and physical tools have been developed as substitutes for cold winters. Hydrogen cyanamide (HC) was widely used around the world (Lavee and May 1997), however, due the negative impact of this molecule on human health, its used has been banned in several countries. Sodium azide (AZ) has similar effects than HC (Pérez et al. 2009) but it has not been used commercially. Alternative treatments such as soaking the buds in hot water and, more recently, the use of cold plasma, has been proposed to stimulate budbreak and release the buds from ED (Halaly et al. 2011; Ben Mohamed et al. 2014; Mujahid et al. 2020). When dormancy release takes place, increase in temperatures is required for growth resumption (Campoy et al. 2011; Fadón et al. 2020).

$\mathrm{ED}$ is generally determined by estimating the time it takes for buds to sprout under forced conditions (Dennis 2003; Rubio et al. 2016). When the time elapsed between sampling and budbreak is long, buds are considered to be endodormant. Recently, methods based on the time to event or survival analysis have been used to evaluate ED and budbreak in grapevines (Cragin et al. 2017; Pérez et al. 2007; Londo and Johnson 2014; Camargo Alvarez et al. 2018). In this study, different treatments that stimulate budbreak of grapevines such as: (a) an increase in temperature during ECD; (b) exposure to chilling temperatures during ED; and (c) the application of dormancy breaking compounds, such as HC and AZ (Pérez et al. 2009) were evaluated in two grapevine cultivars, one early budbreak (Chardonnay) and one late budbreak (Thompson seedless) using the Kaplan-Meier method and the log-rank test.

\section{Material and Methods}

\section{Plant Material}

One-year-old cv. Thompson seedless and Chardonnay rooted during the spring were placed into 1:1:1 (v: v: v) soil:sand:peat in $1 / 3 \mathrm{~L}$ bags. One group of plants remained outdoors, and the other was transferred to the greenhouse on January 10 before their entrance into ED (Vergara and Pérez, 2010). On June 25, the group of plants kept in the greenhouse were pruned, cutting the leaves and green shoots and leaving the central shoot with periderm.

\section{Treatments}

\section{Increase in Temperatures During Eco-Dormancy}

On 26 June, once the buds of Thompson seedless were released from the ED (Vergara and Pérez, 2010), the effect of the increase in temperature on the budbreak of Chardonnay and Thompson seedless was studied. For this, three groups of 5 plants of each cultivar was used to compare the budbreak between grapevines that remained in the greenhouse under controlled conditions at a temperature of $15 \pm 3{ }^{\circ} \mathrm{C}$ with those that were transferred to the growth chamber under forced condition at a temperature of $23 \pm 1^{\circ} \mathrm{C}$.

\section{Effect of Dormancy-Breaking Compounds}

On the same group of plants that remained in the greenhouse, the effects of dormancy breaking compounds were studied, and the following treatments were applied on June 26 and July 22 (a) a $250 \mathrm{ml}$ solution that contains $2 \%$ sodium azide $+1 \%$ unifilm; (b) a $250 \mathrm{ml}$ solution that contains $5 \%$ Dormex (hydrogen cyanamide) $+1 \%$ unifilm; and (c) a $250 \mathrm{ml}$ solution that contains water $+1 \%$ unifilm. Each treatment was applied to 10 plants of each cultivar, and budbreak was assessed every 5 days for one month in the greenhouse.

\section{Effect of Chilling During Endodormancy}

To analyse the effect of chilling, three group of 5 plants of each cultivar that remained outdoors until 22 July and accumulated 580 chilling hours were transferred to the greenhouse and their budbreak was compared with those that remained in the greenhouse without being exposed to the cold. The budbreak was analysed weekly for five weeks. On 22 July, the Chardonnay and Thompson seedless grapevines that remained outdoors were at the ECD stage, because at that date $100 \%$ budbreak was obtained after $20 \mathrm{~d}$ under forced conditions. The outdoor temperature was recorded from an automatic metereological station located in the same place at which the experiment were performed and from this record, the chilling hours (Weinberger 1950) were calculated.

\section{Bud Cold Hardiness}

Following the method described by Mills et al. (2006), a device for differential thermal analysis (DTA), the "Kryoscan", was used to measure the cold hardiness of grape dormant buds (Rubio et al. 2016,2019). The DTA was performed with a freezing and data acquisition device that uses Peltier elements for the cooling and detection modules (Badulescu and Ernst 2006). Two peaks were observed, one corresponded to the high temperature exotherm (HTE), which was assigned to the freezing point of extracellular (apoplast) water that is non-lethal (Burke et al. 1976), and the other to the low thermal exotherm (LTE), which was assigned to the freezing point of intracellular water that is lethal (Burke et al. 1976). Due to that the lethal damage to the grapevine buds occurs at temperatures equal or less than LTE, the lowest temperature that the grapevine bud can resist without 
damage corresponds to its LTE value, which is a measure of its cold hardiness (Ferguson et al. 2011; Mills et al. 2006; Pierquet and Stushnoff 1980). Each value corresponds to the average of 16 biological replicates of single buds.

\section{Data Analysis}

The time required to budbreak of each sample and cultivar, including right-censored observations of the buds that did not break during the treatment, were adjusted to the survival distribution function by the non-parametric Kaplan-Meier (KM) method. The KM method calculates the percentage or probability of the absence of bud-break as a function of time after sampling. However, for practical reasons Camargo Alvarez et al. (2018) used the complement of the probability or percentage of the absence of bud-break, which correspond to the probability or percentage of budbreak. A log-rank test was carried out to compare the estimated survival distribution of the control samples against the treated samples. A significant difference indicates differences in the budbreak distribution curve, and the larger the value of the Chi-squared $\left(\chi^{2}\right)$ is, the greater the difference between the control and treated samples. Survival analysis, or time to event analysis, is a category of statistical methods designed specifically to handle a response variable that measures the elapsed time until a specific event occurs (here, budbreak), which may be censored (Klein and Moeschberger 2003). Kaplan-Meier survival curves are the simplest way to estimate survival over time when data are censored (Altman and Bland 1998). The survival analysis was carried-out with Minitab statistical software.

\section{Results}

\section{Effect of Low Temperatures on the Bud Cold Hardiness of Chardonnay and Thompson Seedless Grapevines}

The bud cold hardiness of both cultivars was measured by DTA in grapevines that remained in the greenhouse and outdoors. The grapevines that remained outdoors accumulated 580 chilling hours (Weinberg 1950) and the LTE of their buds was lower than that of the grapevines that remained in the greenhouse (without chilling accumulation) (Fig. 1). This result indicates that grapevines that remained outdoors acclimatized to the cold, while those that remained in the greenhouse were not cold acclimatized. Interestingly, no significant differences between the bud LTE of both grapevine cultivars was observed when they remained outdoors and exposed to 580 chilling hours. This result indicates a similar capability of both cultivars to acclimatize to the cold (Fig. 1).

\section{Effect of Low Temperatures on the budbreak of Chardonnay and Thompson Seedless Grapevines}

The budbreak of both cultivars was measured by survival analysis in grapevines that remained in the greenhouse and outdoors during the entire period of the ED. The results showed that in both cultivars, the time required to reach $50 \%$ budbreak was shorter in grapevines that remained outdoors (Fig. 2). However, the effect of cold exposure on reducing the time required to reach $50 \%$ budbreak was greater in Chardonnay than in Thompson seedless grapevines, as reflected by the greater Chi-squared $\left(\chi^{2}\right)$ obtained between the control buds (not exposed to cold) and the buds exposed to cold (Fig. 2; Table 1).

\section{Effect of the Temperature Rise on the Budbreak of Chardonnay and Thompson Seedless Grapevines}

The effect of the temperature rise on the budbreak of both cultivars was studied in grapevines that have completed their ED cycle (July 22). The budbreak was determined in one group that remain in the growth chamber $\left(23 \pm 1{ }^{\circ} \mathrm{C}\right)$, and in another group that remained in the greenhouse $\left(15 \pm 3{ }^{\circ} \mathrm{C}\right)$. The results indicate that the rise in temperature during the ECD period significantly improved the budbreak of both cultivars, as indicated by the high value of the $\chi^{2}$ obtained between the budbreak of plants kept in the greenhouse (control) and in the growth chamber (Fig. 3). However, the effect of the temperature rise was greater on Chardonnay's buds than on those of the Thompson seedless grapevines (Fig. 3; Table 2).

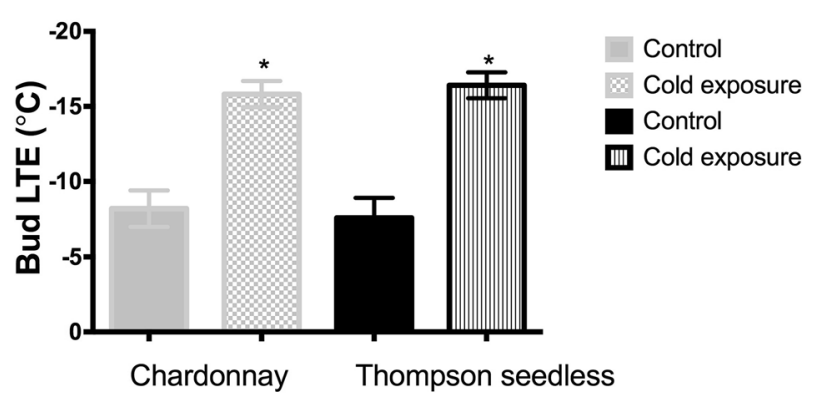

Fig. 1 Cold-exposure of Vitis vinifera cultivars Chardonnay and Thompson seedless during their endodormancy period increased the cold hardiness of their buds relative to the buds of plants not exposed to cold. The bud cold hardiness was determined by the low thermal exotherm (LTE) of buds collected from plants that remained outdoors until July 22 and accumulated 580 chilling hours and from plants that remained in the greenhouse without chilling accumulation. Values are the average of 16 buds, and bars represent \pm sd 


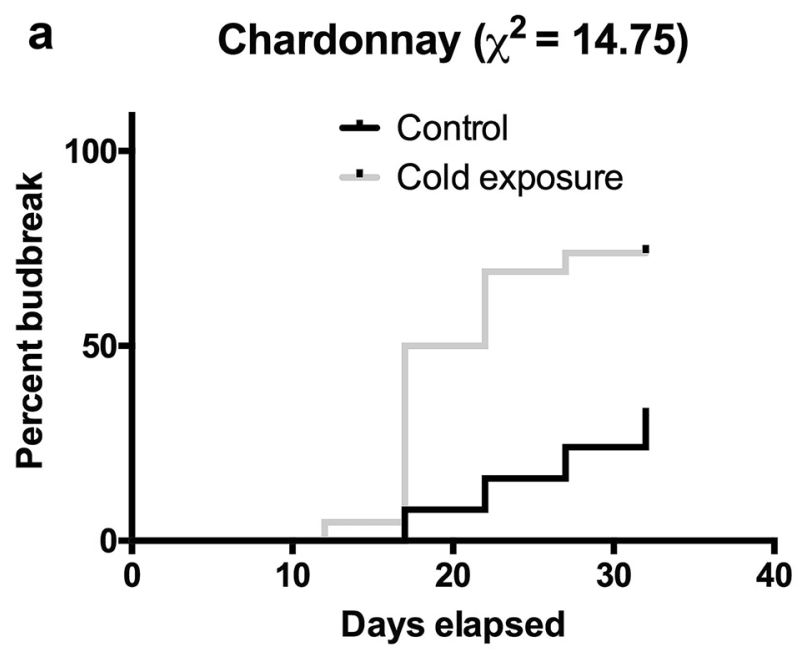

b Thompson seedless $\left(\chi^{2}=6.75\right)$

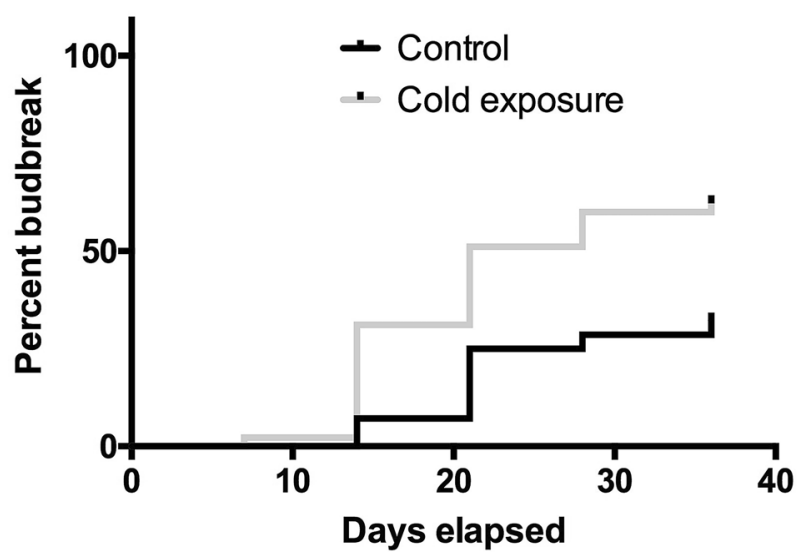

Fig. 2 Kaplan-Meier survival curves for the budbreak of a Chardonnay and $\mathbf{b}$ Thompson seedless unexposed (control) and exposed to cold during their endodormancy period. The budbreak measurements were performed under greenhouse conditions from July 22 onwards

Table 1 Log-rank comparison between the Karl-Meier survival function, for the sprouting of control buds (not exposed to cold), and buds exposed to the cold of the Chardonnay and Thompson seedless cultivars

\begin{tabular}{lcc}
\hline & Chi-square $\left(\chi^{2}\right)$ & $P$-value \\
\hline Chardonnay & 14.75 & $<0.01$ \\
Thompson seedless & 6.67 & $<0.05$ \\
\hline
\end{tabular}

\section{Effect of Dormancy-Breaking Compounds on the Budbreak of Chardonnay and Thompson Seedless Grapevines}

Dormancy-breaking compounds $\mathrm{HC}$ and $\mathrm{AZ}$ were applied on June 26 and July 22, which corresponds to the periods of ED and ECD, respectively (Vergara and Pérez, 2010), and budbreak was assessed every 5 days in the greenhouse. The results
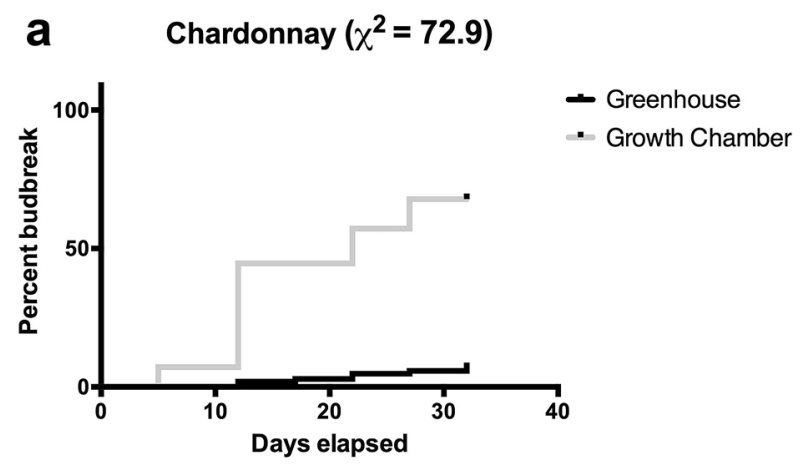

b Thompson seedless $\left(\chi^{2}=27.3\right)$

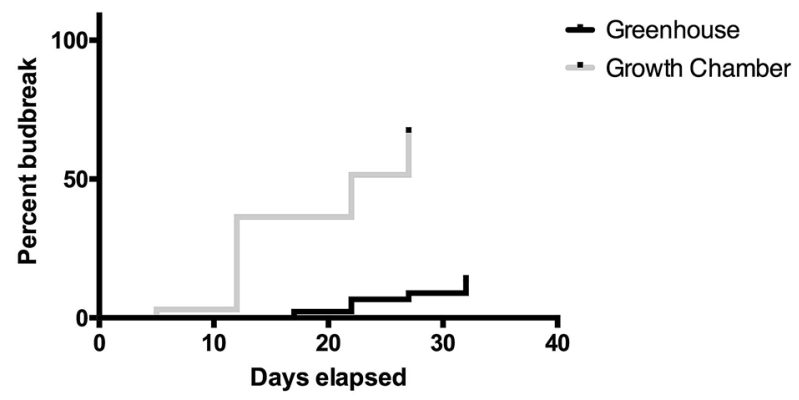

Fig. 3 Kaplan-Meier survival curves for the budbreak of a Chardonnay and $\mathbf{b}$ Thompson seedless under greenhouse and growth chamber conditions

Table 2 Log-rank comparison between the Karl-Meier survival function, for the sprouting of buds in the greenhouse and in the growth chamber

\begin{tabular}{lll}
\hline & Chi-squared $\left(\chi^{2}\right)$ & $P$-value \\
\hline Chardonnay & 72.9 & $<0.001$ \\
Thompson seedless & 27.3 & $<0.005$ \\
\hline
\end{tabular}

The analysis was carried-out in two grapevine cultivars, Chardonnay and Thompson seedless

showed significant differences between the budbreak of control vines and those treated with $\mathrm{AZ}$ and $\mathrm{HC}$ when the applications were made on June 26 (Fig. 4a, b). However, when the applications were made on July 22, no significant differences were detected between the control and treated grapevines (Fig. 4c, d). The effect of both compounds was greater in Chardonnay than in Thompson seedless grapevines, as reflected by the values of the $\chi^{2}$ between the treated and non-treated grapevines, and in Chardonnay, the effect of $\mathrm{AZ}$ was greater than that of HC (Table 3). 


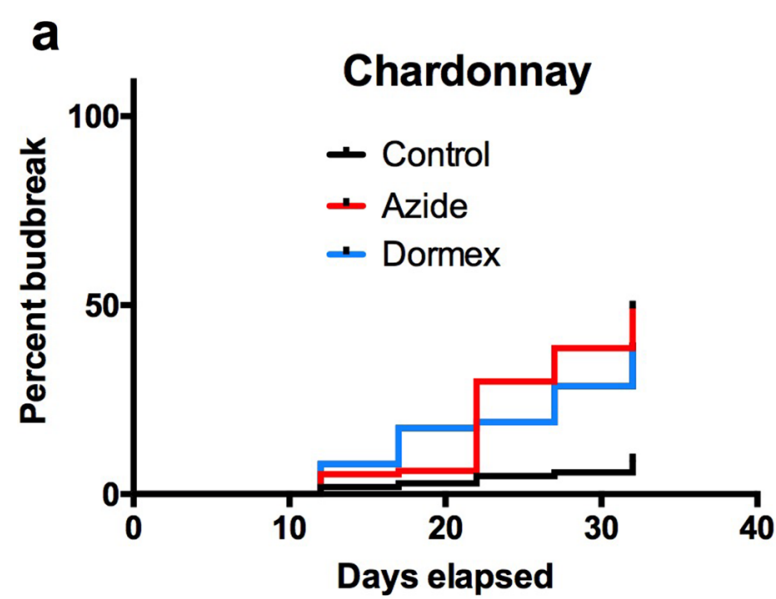

C

Chardonnay

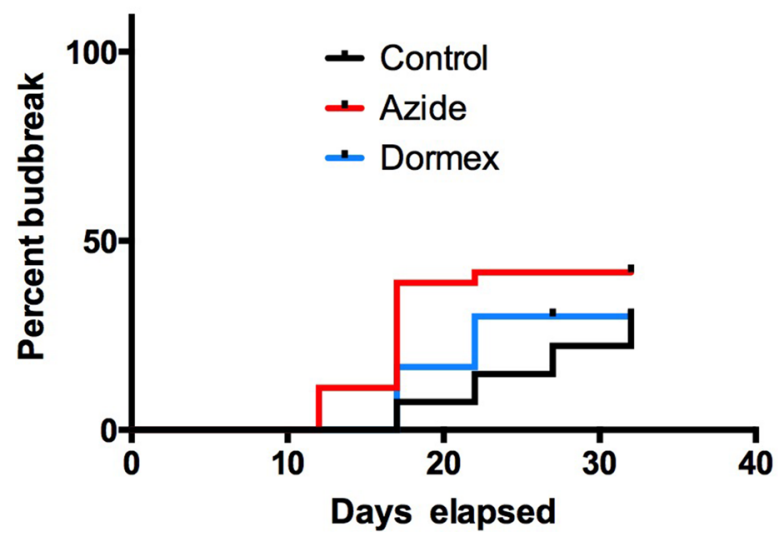

Fig. 4 Kaplan-Meier survival curves for the sprouting of control buds and those treated with sodium azide and hydrogen cyanamide during $\mathbf{a}, \mathbf{b}$ endodormancy and $\mathbf{c}, \mathbf{d}$ after endodormancy release. The

Table 3 Log-rank comparison between the Karl-Meier survival function, for the sprouting of control buds and buds that were treated with hydrogen cyanamide (HC) and sodium azide (AZ) on

\begin{tabular}{lcc}
\hline & Chi-squared $\left(\chi^{2}\right)$ & $P$-value \\
\hline${ }^{\mathrm{a}}$ Chardonnay (HC) & 25.7 & $<0.01$ \\
${ }^{\mathrm{a}}$ Chardonnay (AZ) & 38.8 & $<0.01$ \\
${ }^{\mathrm{a}}$ Thomson seedless (HC) & 9.16 & $<0.05$ \\
${ }^{\mathrm{a}}$ Thompson seedless (AZ) & 9.84 & $<0.01$ \\
${ }^{\mathrm{b}}$ Chardonnay (HC) & 1.43 & $>0.05$ \\
${ }^{\mathrm{b}}$ Chardonnay (AZ) & 0.47 & $>0.05$ \\
${ }^{\mathrm{b}}$ Thomson seedless (HC) & 2.68 & $>0.05$ \\
${ }^{\mathrm{b}}$ Thompson seedless (AZ) & 3.64 & $>00.5$ \\
\hline
\end{tabular}

a June 26 (endodormancy) and ${ }^{\mathrm{b}}$ July 22 (ecodormancy) b

Thompson seedless

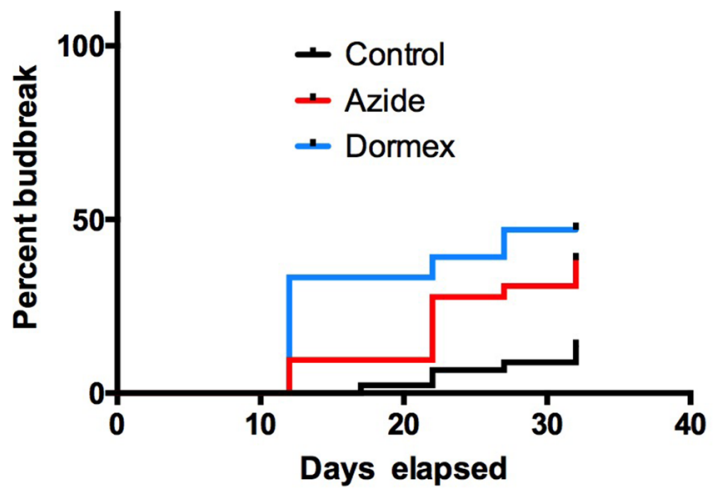

d Thompson seedless

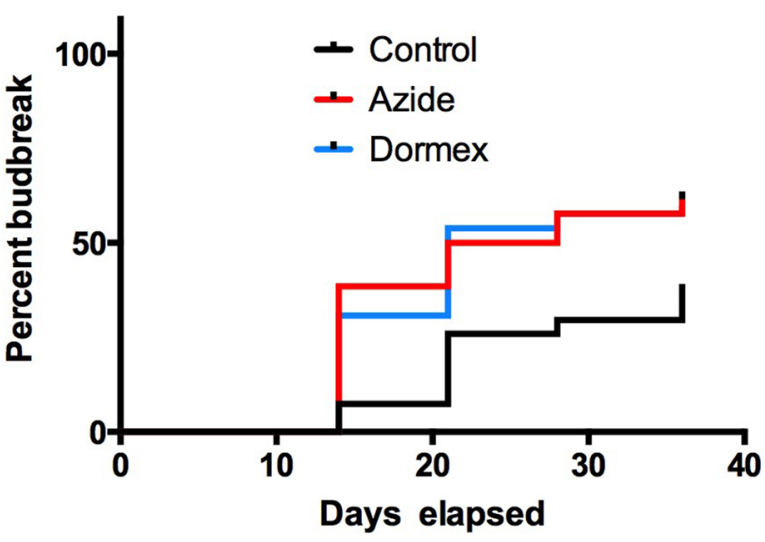

budbreak measurements were carried-out under greenhouse conditions in the Chardonnay and Thompson seedless cultivars

\section{Discussion}

For deciduous fruit trees such as grapevines, bud dormancy is a crucial step as their progress during winter determines the quality of sprouting, flowering, and fruit setting (Beauvieux et al. 2018). Bud dormancy is a complex process, and depending on the factor that inhibits bud growth, it has been classified as para-dormancy (PD), where growth is inhibited by factors external to the bud, endodormancy (ED), where growth is inhibited by internal factors, and eco-dormancy (ECD) where growth is inhibited by environmental factors (Lang 1987). Before budbreak occurs, the buds of deciduous fruit trees move from PD to ED, a phenomenon that is induced by low temperatures or by the shortening of the photoperiod (Maurya and Bhalerao, 2017). To break free from the state of ED and move towards ECD, the buds need to accumulate cold, and finally to budbreak they need to accumulate heat. In the context of global warming, the release 
of buds from the ED can be a critical step due to insufficient cold accumulation, which affects the quality and uniformity of flowering and therefore leads to a drastic reduction in fruit production (Beauvieux et al. 2018; Fadón et al. 2020). Here, the effect of different stimuli that induce budbreak in the grapevine as: (1) exposure to low temperatures during the ED period (2) exposure to high temperatures during the ECD period and (3) the application of agents chemicals such as $\mathrm{HC}$ and $\mathrm{AZ}$, were studied in an early budbreak variety, such as Chardonnay and in a late-budbreak variety, such as Thompson seedless.

\section{Relationship Between Bud Cold-Hardiness and Budbreak}

The exposure to low temperature during ED (580 chilling hours), increased the budbreak and the bud cold-hardiness of both cultivars; however, the increase in budbreak was greater in Chardonnay than in Thompson seedless cultivar (Fig. 2), while the degree of bud cold-hardiness was the same for both cultivars (Fig. 1). Interestingly, the physiological, biochemical and molecular changes induced by the development of cold hardiness such as, the increase in the expression of antioxidant genes (Rubio et al. 2019), and the increase in the expression of genes coding for starch degrading enzymes (Rubio et al. 2016), could be important for the subsequent budbreak. The grapevine bud is relatively hypoxic at the earliest stages of budbreak ( $3 \mathrm{~h}$ ), followed by a considerable oxygenation within $24 \mathrm{~h}$ (Meitha et al. 2015, 2018). Therefore, the transition from an anaerobic to an aerobic condition occurs rapidly within the bud tissue, which must be prepared to face this situation. Therefore, the physiological, biochemical and molecular changes induced by the development of cold hardiness may impact the budbreak, and it is possible to envisage that the degree of cold hardiness achieved by the buds would be related to their subsequent budbreak potential and, therefore, the greater the cold hardiness achieved by the buds, the better their subsequent budbreak will be. Our results, agree partially with this hypothesis, since the dormant buds of the same cultivar exposed to low temperatures increased their cold hardiness and their budbreak in relation to buds that were not exposed to low temperatures. However, when the comparison is performed between the two cultivars, although their buds reached a similar degree of cold hardiness, the budbreak of Chardonnay was greater than that of Thompson seedless. However, since both low and high temperatures are important in the budbreak response, the better budbreak of Chardonnay could be due to the fact that they respond better to temperature increase than Thompson (Fig. 3). Consequently, the hypothesis that the greater the degree of resistance to cold that the buds reach, the greater their capacity for subsequent budbreak, is only valid for the same cultivar, since when comparing between cultivars, other factors may intervene in addition to low temperatures that affect budbreak.

\section{Heat Requirements}

The heat requirement (HR) is another factor that affects the budbreak of deciduous fruit trees (Citadin et al. 2001). In this study, the effect of raising the temperature from $15 \pm 3{ }^{\circ} \mathrm{C}$ (green house conditions) to $23 \pm 1{ }^{\circ} \mathrm{C}$ (forced condition) had a significant effect on the budbreak of both $V$. vinifera cultivars; however, the effect was greater in Chardonnay's buds than in the Thompson seedless ones, a result that supports why even though the buds of both cultivars reach the same degree of cold hardiness after being exposed to 580 chilling hours, Chardonnay's buds sprout better.

\section{Dormancy Breaking Agents}

It has been demonstrated that the dormancy-breaking compounds reduced the content of ABA in the grapevine buds by activating the transcription of the ABA catabolic gene VvA8H3 (Zheng et al. 2015,2018; Vergara et al. 2017), and in this way, they can release the buds from ED earlier. It has also been shown that the effects of these compounds depend on their time of application, and thus, their effect gradually decreases as the buds approach the end of their ED period (Vergara and Pérez 2010; Zheng et al. 2015). Here, we confirm that the effects of $\mathrm{HC}$ and $\mathrm{AZ}$ on budbreak depend on the time of application. Thus, a greater effect was observed in both cultivars when the applications were performed on June 25 (ED), while when they were performed on July 22 (ED released), they had no effect, indicating that at this date, the ED period was finished. The greater effect of dormancy-breaking compounds on Chardonnay's buds than on Thompson's seedless could also be due to the higher response of the former to the increase in temperatures.

\section{Conclusion}

In conclusion, the budbreak of the grapevine that were exposed to chilling temperatures during ED increased significantly compared to that of the grapevine buds that were not exposed to chilling temperatures. This improvement in budbreak could be associated with the physiological and molecular changes produced by the development of bud cold hardiness. Consequently, for the same cultivar, an increase in the bud cold hardiness will increase the bubreak potential of the buds. On the other hand, an increase in temperature during ECD is an important environmental cue that promotes budbreak, and the response of the ecodormant buds to temperature increases was greater in Chardonnay than in Thompson seedless grapevines . 
Acknowledgements The financial support of Fondecyt Project 1190057 is gratefully acknowledged.

Author Contributions FP planned the experiments, SR and FP performed the experiments, and FP wrote the paper.

\section{Compliance with Ethical Standards}

Conflict of interest The author declare that they have no conflict of interest.

Open Access This article is licensed under a Creative Commons Attribution 4.0 International License, which permits use, sharing, adaptation, distribution and reproduction in any medium or format, as long as you give appropriate credit to the original author(s) and the source, provide a link to the Creative Commons licence, and indicate if changes were made. The images or other third party material in this article are included in the article's Creative Commons licence, unless indicated otherwise in a credit line to the material. If material is not included in the article's Creative Commons licence and your intended use is not permitted by statutory regulation or exceeds the permitted use, you will need to obtain permission directly from the copyright holder. To view a copy of this licence, visit http://creativecommons.org/licenses/by/4.0/.

\section{References}

Altman DG, Bland JM (1998) Time to event survival data. BMJ 317:468-469

Arora R, Rowland LJ, Tanino K (2003) Induction and release of bud dormancy in woody perennials: a sciencecomes of age. HortSci 38:911-921

Badulescu R, Ernst M (2006) Changes of temperature exotherms and soluble sugar in grapevine (Vitis vinifera $\mathrm{L}$ ) buds during winter. $\mathrm{J}$ Applied Bot Food Qual Angewandte Botanik 80:165-170

Beauvieux R, Weden B, Dilewander E (2018) Bud dormancy in perennial fruit tree species: a pivotal role for oxidative cues. Front Plant Sci 9:657

Ben Mohamed H, Zrig A, Geuns JMC, Khemira H (2014) Near'lethal heat treatment induced metabolic changes associated with endodormancy release of Superior seedless grapevine cv (Vitis vinifera) buds. Aust J Crop Sci 8(4):486-494

Burke MJ, Gusta LV, Quamme HA, Weiser CJ, Li PH (1976) Freezing and injury in plants. Ann Rev Plant Physiol 27:507-528

Camargo Alvarez H, Salazar-Gutierrez M, Zapata D, Keller M, Hoogenboom G (2018) Time to event analysis to evaluate dormancy status of single-bud cuttings: an example for grapevines. Plant Methods 14:94

Campoy JA, Ruiz D, Egea JA (2011) Dormancy in temperate fruit trees in global warming context: A review. Sci Hort 130:357-372

Citadin I, Raseira MCB, Herter FG, Baptista da Silva J (2001) Heat requirement for blooming and leafing in peach. HortSci 36:305-307

Cragin J, Serpe M, Keller M, Shellie K (2017) Dormancy and coldhardiness transition in wine grape cultivars Chardonnay and Cabernet Sauvignon. Am J Enol Vitic 68:195-202

Dantas D, Bressan-Smith R, Noriega X, Pérez FJ (2020) Buds of Italia melhorada grapevines grown under tropical conditions develop a quiescent state. Env and Exp Botany 171:103951

Dennis G (2003) Problems in standardizing methods for evaluating the chilling requirements for the breaking of dormancy in buds of woody plants. HortSci 38:347-350
Dokoozlian N (1999) Chilling temperature and duration interact on the budbreak of Perlette grapevine cuttings. HortSci 34:1-3

Fadón E, Fernández E, Behn H, Luedeling E (2020) A conceptual framework for winter dormancy in deciduous trees. Agronomy $10: 241$

Faust M, Erez A, Rowland LJ, Wang SY, Norman HA (1997) Bud dormancy in perennial fruittrees: physiological basis for dormancy induction, maintenance and release. HortSci 32:623-629

Ferguson JC, Tarara JM, Mills LJ, Grove GG, Keller M (2011) Dynamic thermal-time model of cold-hardiness for dormant grapevine buds. Ann Bot 107:389-396

Grant TNL, Gargrave J, Dami IE (2013) Morphological physiological, and biochemicalchanges in Vitis genotype in responses to photoperiod regimes. Am J Enol Viti 64:466-475

Halaly T, Zion B, Arbel A, Regev R, Barak M, Or E (2011) Short exposure to sublethal heat shock facilitates dormancy release in grapevines. Am J Enol Viti 62:106-112

Jian L, Li PH, Sun L, Chen TH (1997) Alterations in ultrastructure and subcellular localization of $\mathrm{Ca}^{2+}$ in poplar apical bud cells during the induction of dormancy. J Exp Bot 48:1195-1207

Klein J, Moeschberger M (2003) Survival analysis techniques for censored and truncated data. In: Dietz K, Gail M, Krickeberg K, Tsiatis A, Samet J (eds) ACM SIGPLAN notices, 2nd edn. Springer, New York

Kühn N, Ormeño-Nuñez J, Jaque-Zamora G, Pérez FJ (2009) Photoperiod modifies the diurnal expression profile of VvPHYA and VvPHYB transcripts in field grown grapevine leaves. J Plant Physiol 166:1172-1180

Lang GA (1987) Dormancy: a new universal terminology. HortSci 22:817-820

Lavee S, May R (1997) Dormancy of grapevine buds-facts and speculation. Aust J of Grape Wine Res 3:31-46

Londo JP, Johnson LM (2014) Variation in the chilling requirement and budburst rate of wild Vitis species Env. Exp Bot 106:138-147

Luedeling E, Zhang M, Girvetz EH (2009) Climatic change lead to declining winter chill for fruit and nut trees in California during 1950-2009. PLoS ONE 4(7):e6166

Luedeling E (2012) Climate change impacts on winter chill for temperate fruit and nut production: A review. Sci Hort 144:218-229

Maurya JP, Bhalerao RP (2017) Photoperiod and temperature mediated control of growth cessation and dormancy in trees: a molecular perspective. Ann Bot 120:351-360

Meitha K, Konnerup D, Colmer TD, Considine JA, Foyer CH, Considine MJ (2015) Spatio temporal relief from hypoxia and production of reactive oxygen species during bud burst in grapevine (Vitis vinifera). Ann Bot 116:703-711

Meitha K, Agudelo-Romero P, Signorelli S, Gibbs DJ, Considine JA, Foyer CH, Considine MJ (2018) Developmental control of hypoxia during bud burst in grapevine. Plant Cell Environ 41:1154-1170

Mills LJ, Ferguson JC, Keller M (2006) Cold-hardiness evaluation of grapevine buds and canes tissues. Am J Enol Viti 57:194-200

Mujahid Z, Tounekti T, Khemira H (2020) Cold plasma treatment to release dormancy and improve growth in grape buds: a promising alternative to natural chilling and rest breaking chemicals. Sci Rep 10:2667

Parada F, Noriega X, Dantas D, Bressam-Smith R, Pérez FJ (2017) Differences in respiration between dormant and non-dormant buds suggest the involvement of ABA in the development of endodormancy in grapevines. J Plant Physiol 201:71-78

Pérez FJ, Rubio S, Ormeño-Nuñez J (2007) Is erratic budbreak in grapevines grown in warm-winter areas related to disturbances in mitochondrial respiratory capacity and oxidative metabolism? Fun Plant Biol 34:624-632 
Pérez FJ, Vergara R, Or E (2009) On the mechanism of dormancy release in grapevine buds: a comparative study between hydrogen cyanamide and sodium azide. Plant Growth Regul 59:145-152

Pierquet P, Stushnoff, (1980) Relationship of low temperature exotherms to cold injury in Vitis riparia Michx. Am J Enol Viti $31: 1-6$

Rinne PJH, Welling A, Vahala J, Ripel L, Ruonala R, Kangasjarvi J, van der Schoot C (2011) Chilling of dormant buds hyperinduce FLOWERING LOCUS T and recruitsGA-inducible 1,3-beta-glucanase to reopen signal conduits and release dormancy in Popullus. Plant Cell 23:130-146

Rubio S, Dantas D, Bressan-Smith R, Pérez FJ (2016) Relationship between endodormancy and cold-hardiness in grapevine buds. $\mathrm{J}$ Plant Growth Reg 35:266-275

Rubio S, Noriega X, Pérez FJ (2019) Abscisic acid (ABA) and low temperatures synergisticallyincrease expression of $\mathrm{CBF} / \mathrm{DREB} 1$ transcription factor in grapevine dormant buds. Ann Bot 123:681-689

Vergara R, Pérez FJ (2010) Similarities between natural and chemically induced bud-endodormancy release in grapevine Vitis vinifera L. Sci Hortic 125:648-653
Vergara R, Noriega X, Pérez FJ (2017) ABA represses the expression of cell cycle genesan may modulate the development of endodormancy in grapevine buds. Front in Plant Sci 8:812

Weinberg JH (1950) Chilling requirements of peach varieties. Proc Am Soc Hort Sci 56:122-128

Zheng C, Halaly T, Acheampog AK, Takebayashi Y, Jikumaru Y, Kamiya Y, Or E (2015) Abscisic acid (ABA) regulates grape bud dormancy, and endodormancy release stimuli may act through modification of ABA metabolism. J Exp Bot 66:1527-1542

Zheng C, Acheampong AK, Shi Z, Mugzech A, Halaly-Basha T, Shaya F, Sun Y, Colova V, Mosquna A, Ophir R, Galbraith DW, Or E (2018) Abscisic acid catabolism enhances dormancy release of grapevine buds. Plant Cell Environ. 41:1-14

Publisher's Note Springer Nature remains neutral with regard to jurisdictional claims in published maps and institutional affiliations. 